\section{Ayabuasca: expansão de usos rituais e de formas de apreensão científica}

B. C. LABATE e W. S. ARAÚJO (orgs.), O uso ritual da ayahuasca. Campinas/São Paulo, Mercado de Letras/Fapesp, 2002. 686 páginas.

\section{Edmundo Pereira}

Ao terminarmos a leitura de O uso ritual da ayahuasca ficam evidentes a diversidade e a complexidade do fenômeno, tanto do que diz respeito à variabilidade de usos rituais e contextos sóciohistóricos a que somos apresentados, como aos modos de apreensão, descrição e análise desses usos pela ciência - em particular a antropologia, a medicina, a psicologia e a farmacologia. Nesse sentido, a publicação alcança seus objetivos: apresenta um rico panorama das pesquisas desenvolvidas sobre o tema ao longo dos 25 artigos que compõem o volume, contribuindo para um melhor entendimento do fenômeno a partir das lógicas locais, da relevância e da significação que têm para os que estão envolvidos em seus usos rituais. Inicialmente pensado para reunir as conferências apresentadas no "I Congresso sobre Uso Ritual da Ayahuasca" (Campinas, 1997) e depois acrescido de textos de pesquisadores que não participaram do evento mas que têm trabalhos consolidados na área, o livro é uma excelente entrada nesse campo de estudos que abarca o trabalho de gerações de pesquisadores, no Brasil tendo se desenvolvido especialmente na última década.

Assim como em outras áreas de pesquisa em torno de temas amazônicos, o estudo do uso da ayahuasca desenvolveu-se sobretudo a partir dos anos de 1970. Entre os nomes mais antigos atribuídos à bebida feita da infusão do cipó Banisteriopsis caapi - no Brasil chamado de "jagube" - com a folha do arbusto Psychotria viridis - conhecido como "rainha" -, está o de ayahuasca. O termo é traduzido do quíchua como "cipó dos mortos" ou "cipó dos espíritos", o que nos remete a uma de suas significações: a de ser instrumento de reencontro com os antepassados. Tornou-se a denomi- nação de uso corrente tanto entre aqueles que participam dos rituais, como no âmbito dos estudos científicos. No Brasil, outro termo muitíssimo utilizado para referir-se à bebida é "daime". Seu consumo, tanto entre índios, como entre não-índios, realiza-se no interior de práticas ritualísticas específicas, práticas que corroboram certos princípios ético-morais norteadores.

A organização do livro em três partes reflete tanto a expansão do uso indígena da bebida para o curandeirismo caboclo, daí à formação das religiões daimistas brasileiras, chegando aos círculos internacionais da Nova Era, como a démarche epistemológica desse campo de estudos. Além disso, acompanhamos o desenvolvimento dos estudos farmacológicos sobre os princípios ativos da ayahuasca e suas especificidades, tomados como uma experiência somatológica e cultural. Após os textos introdutórios do antropólogo Mauro Almeida e dos organizadores do volume, que apontam para questões e constatações gerais de ordem analítica e empírica, temos a primeira parte do livro, intitulada "Ayahuasca entre os povos da floresta".

Dentro da categoria "povos da floresta" (que mereceria uma nota explicitando o porquê de sua escolha), somos apresentados ao uso ritual da ayahuasca entre grupos indígenas, caboclos peruanos e colombianos, e seringueiros brasileiros. O primeiro dos sete artigos que compõem essa parte, do antropólogo Pedro Luz, apresenta um mapeamento bibliográfico da literatura sobre os grupos indígenas Pano, Aruák e Tukano, dedicada especialmente ao uso da Banisteriopsis. Uma constatação etnográfica importante enfatizada por Luz (p. 63) é a de que o uso ritual da ayahuasca em contexto indígena é um dos fatores fundamentais que contribui para a coesão dos grupos, epicentro dos sistemas de crenças, das relações com o cosmos e com os antepassados e de processos terapêuticos de cura corporal e espiritual. O autor expõe também o instrumental analítico desenvolvido para apreender o fenômeno, sobretudo a literatura dedicada ao "xamanismo".

No artigo de Jean Langdon, dentro de uma proposta de abordagem "transdiciplinar" - que, aliás, marca o volume de um modo geral - , uma 
bela narrativa Siona introduz o leitor à ritualística e aos processos de transmissão de conhecimento envolvidos no consumo da ayahuasca entre o grupo. Langdon enfatiza que a experiência, além de ser uma construção subjetiva e neurofisiológica, é "permeada de orientações culturais" (p. 68), ou seja, "a experiência faz parte da comunidade como um todo, e não só do xamã" (p. 69). O mesmo aplica-se à "práxis alucinógena" (p. 95) kaxinawá apresentada por Barbara Keifenhem sobretudo por meio das noções nativas de ver e visualizar, ao final apontadas como sendo "holísticas", englobando o cotidiano e o extraordinário, o sonho e a realidade. Aqui, como em Langdon, o contexto cultural é enfocado dentro da complexidade da experiência com a ayahuasca, contexto que promove a padronização de certos estoques imagéticos compartilhados pelo grupo. A dimensão musical do fenômeno, aludida em vários artigos do volume, é também enfatizada como fundamental para a condução e a salvaguarda do ritual, como expresso no canto kaxinawá apresentado por Keifenhem: "E no caminho sonoro nós todos sairemos da embriaguez do nixi pae" (p. 103).

Vale ressaltar que ao longo do volume somos apresentados não só às várias realidades etnográficas, mas também à formação de metodologias de trabalho e instrumentos heurísticos para apreender cientificamente essas realidades, dado subjacente ao modo como somos introduzidos aos diversos usos rituais da ayahuasca. De toda a maneira, é possível situar e posicionar os autores e as propostas de abordagem para uma melhor compreensão das análises e dos dados apresentados no encadeamento dos artigos. Noções que respondem a realidades etnográficas e analíticas específicas, como, por exemplo, a de "vôo xamânico" (ver a etnografia Siona e Kaxinawá apresentadas por Langdon e Keifenheim, respectivamente), passaram a ser instrumentos heurísticos potentes e de uso corrente, por vezes abusivo, não só para a descrição, a interpretação e a análise dos casos indígenas, mas também para instrumentalizar o estudo dos usos que a ayahuasca adquiriu nos últimos séculos (como curandeirismo caboclo e doutrina religiosa), ainda que não refletindo as categorias nativas de uso corrente.
O artigo do médico Germán Zuluaga marca seu lugar na proposta da edição de compor um quadro polifônico, por vezes conflitivo, das vertentes e dos atores envolvidos - entre "nativos" e "pesquisadores" - nesse campo de estudos e de práticas. Sua argumentação acaba se tornando frouxa e pouco precisa ante a veemência de seu principal argumento, qual seja, o de desqualificar toda e qualquer prática envolvida no consumo do chá (seja ritual, seja científica), exceto as exercidas pelas populações indígenas. Contrapondo-se ao uso não-indígena, ao que o autor chama de "levianas formas de uso e interpretação sobre seus efeitos", "apropriação por parte do homem branco, de uma sabedoria e um bem indígena" (p. 135), o consumo da ayahuasca no meio indígena é apresentado como reminiscências de uma ciência original, denominada "saber xamânico" (p. 139). A esse texto segue-se o trabalho de outro médico, Jacques Mabit, que busca compreender o fenômeno sobretudo a partir de suas possíveis propriedades "etnomédicas" (p. 148). Evocando o "conhecimento ancestral dos mestres curandeiros da Amazônia peruana" (p. 145) de forma positiva, seus esforços concentram-se em apontar empiricamente a validade dessa prática dentro do que chama "tradições de cura", ou seja, "sistemas de representação mental nas práticas de cura" (p. 147). Além de uma boa etnografia sobre o preparo, o consumo, a significação e o efeito fisiológico da bebida, Mabit apresenta suas experiências como terapeuta no Projeto Takiwasi, no Peru, especialmente no que se refere ao tratamento de toxicomanias.

Ainda no contexto do "xamanismo ribeirinho" (p. 179), Luis Eduardo Luna mostra-nos o universo dos curanderos, ou, como enfatiza o autor, dos "vegetalistas ribeirinhos" da bacia do Alto Amazonas (p. 181). Segundo essa "tradição", "sob certas condições algumas plantas ou 'vegetais', possuidoras de sábios espíritos, teriam a faculdade de 'ensinar' às pessoas que os procuram" (p. 181). Sua origem está ligada ao encontro entre índios e não-índios ao longo dos últimos três séculos.

A dimensão do "segredo" entre seringueiros brasileiros, enfatizam, por fim, a antropóloga Mariana Franco e o seringueiro Osmíldo Conceição 
(p. 200), marca um fenômeno da mesma ordem do curandeirismo peruano e colombiano. No artigo que fecha a primeira parte do volume, somos apresentados ao uso da ayahuasca no Vale do rio Juruá, no Acre. Muito interessante é o fato de podermos acompanhar no decorrer do livro, por meio de metodologias em micro-história, parte da sociogênese de fenômenos por vezes datados de não mais de um século, em que pesam as relações diádicas, familiares e comunitárias - a "lealdade das amizades" (p. 208) - nos caminhos de constituição e institucionalização de práticas rituais associadas ao consumo da ayahuasca. Durante o período de atuação das empresas extrativistas da borracha nas primeiras décadas do século XX, o "aprendizado da ciência da cura" (p. 205) - que no caso brasileiro levaria a "expansão do uso da ayahuasca" (p. 213) à formação de religiões caboclas - acontecia em segredo por conta da perseguição dos patrões seringalistas, para os quais decorria de tais práticas a "displicência para o trabalho" (p. 208).

Nos treze artigos que compõe a segunda parte do volume, "As religiões ayahuasqueiras brasileiras" (terminologia que também mereceria uma nota explicitando o porquê de sua escolha), somos apresentados ao fascinante mundo dessas religiões em sua formação sócio-histórica: o Alto Santo (1930), o Centro Eclético da Fluente Luz Universal Raimundo Irineu Serra (1970), a Barquinha (1945) e a União do Vegetal (1960). Fascinante porque, ainda que recentes historicamente (todas as religiões ligadas ao consumo da Banisteriopsis surgiram no século XX), compõem um quadro rico e complexo de práticas, significações e princípios ético-morais da maior relevância em seus contextos locais. O primeiro trabalho, da antropóloga Beatriz Labate, faz um exaustivo levantamento da "literatura brasileira sobre as religiões ayahuasqueiras" (p. 229) em dois eixos: trabalhos acadêmicos (sobretudo antropológicos) e não-acadêmicos. Os modos de descrição e de interpretação dos usos rituais associados à ayahuasca passam a abranger tanto a literatura sobre "xamanismo", como os estudos dedicados ao "catolicismo popular", ao sincretismo religioso, ao "campesinato" e às "biografias" dos fundado- res. Associam-se, nesse momento da análise, as trajetórias pessoais com as estruturas rituais e ético-morais, o que amplia o campo de visão. Enfim, não só o fenômeno, mas também as formas de apreendê-lo tornam-se mais complexas.

No artigo sobre o Alto Santo - núcleo daimista mais antigo, fundado em 1930 -, da antropóloga Arneide Bandeira Cemin, temos a máxima de Mauss seguida com precisão: "detalhes são essenciais". A autora apresenta uma minuciosa etnografia, desde os níveis técnicos e hierárquicos envolvidos no preparo da bebida e o ideário a este associado, até a organização da liturgia daimista, seus instrumentos e princípios ético-morais norteadores. Fazendo uso original da idéia maussiana de que por meio de técnicas corporais se produz a "vida simbólica do espírito" (p. 279), o leitor toma conhecimento de muitas dessas "técnicas religiosas" (p. 278) como, por exemplo, o fardamento, a concentração, e o bailado.

A antropóloga Sandra Goulart contextualiza de modo revelador a "emergência do Santo Daime" (p. 314). No Brasil, o surgimento de "religiões ayahuasqueiras" no último século deve-se especialmente a alguns personagens. Goulart apresenta-nos a um deles, figura emblemática da cultura religiosa acreana, nascido na baixada maranhense, o ex-seringueiro, "afamado curador", e depois "Mestre", Raimundo Irineu Serra. Aproximando-se do universo daimista do Alto Santo por meio de estudos dedicados à "antiga sociedade rural brasileira" (p. 315), a autora discute a maneira pela qual o "mutirão", as "festas religiosas" e o "compadrio" são elementos que organizam os "bairros amazônicos" (p. 315). Esses elementos também atuariam na formação das religiões ayahuasqueiras. No processo migratório da floresta para as recém-periferias urbanas de Rio Branco, em um desses bairros viria a se constituir o Alto Santo, primeiro núcleo religioso organizado em torno do consumo da ayahuasca.

No caso do antropólogo Fernando de La Rocque Couto, a noção de "xamanismo" é usada como uma ferramenta analítica adaptada ao contexto daimista. Couto propõe entender o Santo Daime como expressão de um "xamanismo coletivo", uma vez que "embora existam os coman- 
dantes do trabalho, a atividade xamânica não é exclusividade apenas de alguns iniciados" (p. 358). Sua leitura enfatiza a dimensão da "ordem" para qualificar o ritual, sublinhando, por exemplo, sua "organização militar" (p. 349).

O ensaio do antropólogo Clodomiro Monteiro Silva analisa o fenômeno da "miração" - "categoria central no culto do Santo Daime" (p. 367) como o elemento que une "culturas indígenas americanas" e "religiões afro-brasileiras", relacionado-o ao fenômeno da "incorporação" ou "irradiação". Sua proposta é a de situar o Santo Daime (constituído em Sistemas de Juramidam - Alto Santo - e Sistemas de Daniel Pereira de Matos Barquinha) entre os cultos afro-amazônicos (p. 369). O autor enfatiza que o estudo de caso desse culto remete a duas "tradições" (p. 368), a indígena e a afro-brasileira, sendo esta última fruto das migrações maranhenses para a região durante o ciclo da borracha, na virada do século XIX para o século XX. Ainda que sua tradução para o termo "daime" a partir do fon pareça etnograficamente insustentável, o fato de analisar o culto do seu enquadramento do culto do Neste Nesse contexto, segundo Silva, o Santo Daime poderia pode ser enquadrado no "horizonte dos cultos afroamazônicos" (p. 371) é traz rendimento profícuo e se justifica, pois realça realçando o fato, no caso, decorrente especialmente do diálogo entre a religião amazônica e o com o culto afro-brasileiro maranhense do Tambor de Mina.

Walter Dias Jr., cientista social, com um tom bastante pessoal, além de apresentar uma boa etnografia do processo de preparo da infusão, é mais um dos autores que propõe uma aproximação "bio-psico-antropo-social" (p. 415) para analisar o uso ritual da ayahuasca. Sua proposta desenvolve-se não só no sentido de promover uma "transdisciplinaridade", mas também de buscar uma forma de se aproximar do fenômeno "baseada no diálogo entre a objetividade e a subjetividade" (p. 424).

Maria Cristina Pelaez, médica e antropóloga, dedica-se a explorar as "potencialidades terapêuticas do Santo Daime, como agente de "cura espiritual"' (p. 427), sobretudo em sua capacidade de "gerar sentimentos de transcendência que possibi- litam a cura de desequilíbrios físicos, mentais ou espirituais" (p. 428). Segundo a autora, a análise dos "complexos eventos neuroquímicos" relacionados ao uso da infusão deve levar em conta que "embora agentes psicodélicos atuem nos mesmos receptores cerebrais e produzam similares mudanças somáticas, psíquicas e perceptivo-sensoriais, eles não determinam per se as características da experiência" (p. 429). Esta é mediada pelos aspectos culturais característicos de cada lugar.

O trabalho do antropólogo Edward MacRae reforça ainda mais essa premissa ao deslocar a ênfase dos detalhes farmacológicos para os de natureza psicológica e sociocultural. O autor responde às críticas às religiões ayahuasqueiras, apontando o "perigo das alegações de 'pureza' e 'originalidade"' (p. 452) como pressupostos de legitimação das experiências ligadas à bebida. Enfatiza, além disso, as dificuldades que a análise geral dos usos rituais ligados à ayahuaca traz a uma aproximação às religiões ayahuasqueiras, "cuja natureza sincrética e cujo distanciamento das tradições indígenas, às vezes, causam incompreensão" (p. 453).

O antropólogo alemão Carsten Balzer trata da contemporaneidade do uso da bebida, que atingiu, sobretudo na última década, cidades como Berlim e Tóquio, no contexto dos "círculos da Nova Era" (p. 462), do "mercado das religiões" (p. 479). Por meio da descrição de um "workshop xamânico" (p. 471), Balzer aponta para o fato de que de acordo com a forma com que é feita sua transposição para contextos socioculturais diversos, o "ritual legendário da Amazônia" (p. 473) pode não trazer os benefícios que tem sido apontados em seus locais originários de uso.

No trabalho do antropólogo Wladimyr Sena Araújo somos introduzidos à Barquinha, Centro Espírita e Culto de Oração Casa de Jesus Fonte de Luz, fundado por Daniel Pereira de Matos em 1945. Seu objetivo é "apresentar o espaço simbólico de uma das religiões da Amazônia" (p. 497). O autor relaciona aspectos da história de vida de Daniel com o corpo simbólico da religião, enfatizando seu caráter plástico, sua "grande velocidade de incorporação e retirada de elementos de práticas religiosas diversas" (p. 506), pelo que a 
imagem da barca é lida qual fosse uma "nau de ressignificação" (p. 508).

Fechando a segunda parte do volume, há três artigos dedicados à União do Vegetal (UDV). Lucia Regina Brocanelo Gentil, antropóloga, e Henrique Salles Gentil, historiador e psicólogo, refazem a trajetória do baiano José Gabriel da Costa que, assim como Irineu Serra e Daniel Mattos, migrou como soldado da borracha para a Amazônia nas primeiras décadas do século XX. "Mestre Gabriel", como ficaria conhecido, fEste seria o fFundariador d a UDV nos anos de 1960, constituindo em seu "corpo doutrinário eclético" (p. 515) nos anos 1960, misto - assim como no caso das demais religiões ayahuasqueiras - de cristianismo com, cultos africanos e indígenas e de seitas espíritas - - o que, aliás, é característico das demais religiões ayahuasqueiras. A . A -, a partir dos anos da década de 1980, a UDV passaria a informam os autores, expandiria expandiru suas ações para centros urbanos como Rio de Janeiro e São Paulo.

O antropólogo Sérgio Brissac, em perspectiva similar, enfatiza a relação entre o percurso de vida de José Gabriel e a constituição da UDV dentro de "uma ampla rede de relações com diversas configurações culturais presentes na sociedade brasileira" (p. 525). Nesse sentido, tanto o catolicismo popular, como o candomblé, e mesmo a capoeira com suas chulas e princípios éticos, são considerados dimensões presentes na constituição desse "rito sincrético afro-indígena" (p. 532).

Finalmente, fechando a segunda parte do volume, o antropólogo Afrânio Patrocínio de Andrade situa o advento da expansão de algumas das religiões ayahuasqueiras, em especial a UDV, dentro de um contexto mais amplo, "um momento novo na história": o "retorno ao encontro com a religião" (p. 543). Enfatizando o caráter iniciático e hierárquico de religiões como a UDV, o autor reconhece as contribuições para o desenvolvimento de seus membros "em termos familiares e sociais" (p.556), mas critica suas facetas autoritárias e dogmáticas, salientado, oportunamente, que "a intolerância religiosa é filha do dogmatismo ortodoxo" (p. 563).

Nos cinco artigos que compõem a terceira e última parte do volume, "Os estudos farmacológi- cos, médicos e psicológicos da ayahuasca”, somos apresentados aos últimos resultados dos estudos psicológicos, médicos e farmacológicos sobre a "única preparação botânica dependente de uma interação sinérgica entre alcalóides ativos" (p. 578) presentes no Banisteriopsis caapi (Beta-carbolina) e na Psycotria viridis (N-Dimetiltriptamina). É essa interação que faz da infusão um potente "alucinógeno de ação rápida" (p. 578), o que, no entanto, não tem demonstrado trazer prejuízos psicosomatológicos, não obstante seu uso prolongado. Uma constatação geral que percorre os artigos finais é a de que, por fim, o consumo da ayahuasca se mostrou de investigação clínica "complexa botanicamente, quimicamente e etnograficamente" (p. 581), o que pode fazer da bebida "a mais sofisticada descoberta farmacológica jamais feita neste mundo arcaico" (p. 671). Tal descoberta deve ser analisada sob múltiplos ângulos, do farmacológico ao cultural, proposta que norteia a maioria dos autores presentes em $O$ uso ritual da ayabuasca.

\section{EDMUNDO PEREIRA é antropólogo, douto- rando no PPGAS - Museu Nacional/UFRJ.}

